\title{
Salivary 8-OHdG Induction by Physical Exercise Training Under Food Restriction
}

\author{
Yoko Yoshino, $^{\mathrm{a}, *}$ and Yoichi Nakagawa ${ }^{\mathrm{b}}$ \\ ${ }^{a}$ Department of Nutrition and Dietetics, Kamakura Women's University, 6-1-3 Ohfuna, Kamakura, Kanagawa 247-8512, \\ Japan \\ ${ }^{b}$ Dry mouth Clinic, Tsurumi University Dental Hospital, and Department of Oral and Maxillofacial Surgery, Tsurumi \\ University School of Dental Medicine, Yokohama, Japan
}

\begin{abstract}
Objective: We previously reported that physical exercise under food restriction induced alterations in saliva secretion, including a decrease in salivary kallikrein activity, while exercise training alone did not affect the overall saliva content. The objective of the present study was to examine the involvement of oxidative stress in alterations of salivary secretion due to physical exercise under food restriction.

Methods: Male ICR mice at 32 weeks of age weighing from 39 to $50 \mathrm{~g}$ were divided into three groups: an exercise group with food restriction (EXP), an exercise group without food restriction (EXA) and a control group (CTL). The EXP group was fed the same amount of diet as the CTL group (pair-feeding). The EXP and EXA groups had access to a "voluntary running wheel" for exercise. The pilocarpine-stimulated whole saliva was collected from the oral cavity by micro-pipette over 15 min for 12 weeks after the beginning of the experiment. The salivary and serum 8-Hydroxy-2'-deoxyguanosine (8-OHdG) were determined.
\end{abstract}

Results: The salivary 8-OHdG levels in the EXP group were significantly higher than in the CTL and EXA groups $(\mathrm{p}<0.01)$.

Conclusion: The alterations of salivary secretion in mice undergoing chronic exercise training under a food-restricted diet may occur as a result of oxidative stress.

Key Words: Saliva, 8-OHdG, Oxidative stress, Exercise training, Food restriction.

\section{INTRODUCTION}

Moderate physical activity has a beneficial effect on the maintenance of health and the prevention of disease [1]. On the other hand, extreme or overly intense physical training appears to have an adverse effect on overall health. Overtraining induces oxidative damage to DNA in the liver [2], and leads to a suppression of mucosal immunity [3]. There are many kinds of sports that require athletes to undergo dietary restriction in addition to intense physical exercise, such as wrestling and boxing. The athletes may therefore be inferred to be under physical and mental stress. A previous experimental study demonstrated that physical exercise in mice under dietary control induced alterations in saliva secretion, while exercise training alone did not affect the saliva contents [4]. The total protein secretion and kallikrein activity decreased by $20-30 \%$ in the physical exercise under dietary-controlled mice between 4 and 12 weeks after the start of the experiments in comparison to the control mice, thus suggesting that signal transduction in the sympathetic nervous system was downregulated, since kallikrein is secreted in response to alpha ${ }_{1}$-adrenergic receptor stimulation [5]. The study suggested that the salivary function was affected by chronic physical and/or mental stress.

*Address correspondence to this author at the Department of Nutrition and Dietetics, Kamakura Women's University, 6-1-3, Ohfuna, Kamakura city, Kanagawa 247-8512, Japan; Tel: +467 44 2111; Fax: +467 44 7131; E-mail: yoshino@kamakura-u.ac.jp
The oxidative stress is related to various mechanisms such as apoptosis, cancer progression inflammation and aging. Concerning salivary gland disease, salivary antioxidants are increased in rheumatoid arthritis patients [6]. The levels of 8-hydroxy-2'-deoxyguanosine (8-OHdG) and hexanoyllysine (HEL) have been shown to increase in the saliva of patients with Sjögren's syndrome, an autoimmune disorder in which immune cells attack and destroy the exocrine glands, and the level of mitochondrial glutamic-oxaloacetic transminase (m-GOT) is significantly correlated with 8OHdG and HEL [7]. 8-OHdG is formed when the guanine in DNA undergoes oxidative damage by reactive oxygen species (ROS) $[8,9]$. It is possible to prove cytotoxicity via oxidative stress by detecting $8-\mathrm{OHdG}$, and $8-\mathrm{OHdG}$ has therefore been widely used as a biomarker of oxidative damage [10].

The purpose of the present study was to clarify the involvement of oxidative stress in alterations of saliva secretions following physical exercise in dietary-controlled mice.

\section{MATERIAL AND METHODOLOGY}

\subsection{Animals}

Thirty-two-week-old male ICR mice (Japan SLC Inc., Shizuoka, Japan), weighting from 39 to $50 \mathrm{~g}$, were used in the present study. The animals were individually housed in plastic cages under regular light/dark conditions (lights on, $0800-2000 \mathrm{~h}$ ) and the room temperature was maintained at 
$23 \pm 1{ }^{\circ} \mathrm{C}$ and the humidity was between 60 and $80 \%$. Animals had access water ad libitum and laboratory pellets (CE2; CLEA Japan, Inc., Tokyo, Japan) twice a day, in the morning (9:30-10:30) and evening (16:30-17:30).

\subsection{Experimental Conditions}

The animals were divided into three groups according to the experimental condition; an exercise with food restriction (EXP), an exercise without food restriction (EXA) and control (CTL). For exercise in the EXP and EXA groups, a "voluntary running wheel" was used. Mice were housed individually in cages equipped with a running wheel $(20-\mathrm{cm}$ in diameter, Shinano Co., Tokyo, Japan). Each wheel revolution was registered by a magnetic switch, which was connected to a counter. The number of revolution was recorded daily $[11,12]$. The EXA and CTL mice were fed ad libitum for an hour twice a day, thus the EXA mice showed more food consumption than the CTL mice. The EXP group was fed the same amount of food as the CTL (pair-feeding).

It is well established that rats fed a liquid diet exhibit a parotid gland atrophy and decrease of salivary protein secretion $[13,14]$. The changes are thought to result from decreased gland function due to the elimination of the requirement for mastication of food. And then, the EXP group was fed the same amount of food as the CTL to compensate the difference of mastication.

\subsection{Collection of Saliva}

Saliva was stimulated by $0.2 \mathrm{ml}$ of pilocarpine $(0.5$ $\mathrm{mg} / \mathrm{kg}$, ip injection, Wako Pure Chemical Ind., Osaka, Japan), and was collected under general anesthesia $(60 \mathrm{mg} / \mathrm{kg}$ body weight of ketamine, Sankyo Co., Tokyo, Japan; and 6 $\mathrm{mg} / \mathrm{kg}$ body weight of xylazine, Bayer chemicals Japan Ltd., Tokyo Japan) at 4,8 , and 12 weeks in the experiment (at the same time of the day). Saliva collection was started 5 min after pilocarpine injection. Saliva was collected from the oral cavity by micropipette for $15 \mathrm{~min}$ and it was placed in micro-centrifuged tubes placed in an ice bath and weighed. After collecting saliva, mice were further anaesthetised with ether and collected blood from an artery. Blood samples were centrifuged at $3,000 \times \mathrm{g}$ for $5 \mathrm{~min}$ to obtain sera. Saliva and sera sample were stored at $-80 \mathrm{C}$ until the analyses were performed.

All experimental procedures were carried out in accordance with the European Convention for the Protection of Vertebrate Animals used for Experimental and Other Scientific Purposes and were approved by the Committee on Animal Care of Tsurumi University School of Dental Medicine.

\subsection{Determination of Saliva and Serum 8-OHdG}

Saliva and sera samples were centrifuged at $5,000 \times \mathrm{g}$ for 5 min. A competitive enzyme-linked immunosorbent assay (ELISA) was conducted for samples in triplicate using an 8OHdG monoclonal antibody (Institute for the Control of Aging, Shizuoka, Japan). A 50- $\mu 1$ aliquot of each saliva or sera supernatant samples was placed in the wells of a 96-well plate and were incubated for $1 \mathrm{hr}$. The wells were washed 3 times with a buffer solution, and $100 \mu$ of an HRPconjugated anti-mouse IgG antibody was added and incubated at room temperature for $1 \mathrm{hr}$. The wells were washed 3 times with wash buffer, and $100 \mu$ l of hydrogen perox- ide/citric acid containing phosphate-buffered 1\% 3, 3', 5, 5'tetramethylbenzidine was added. After $15 \mathrm{~min}, 1 \mathrm{M}$ phosphate buffer was added into the well to stop the reaction. The absorbance of the reaction mixture was measured at $450 \mathrm{~nm}$ with a micro-plate reader (Bio-Rad Laboratories, Inc., USA), and a standard curve was used to determine the amount of 8OHdG present in the test samples.

\subsection{Statistical Analysis}

All results are expressed as the mean \pm SD. The statistical analyses were performed with one-way ANOVA when comparing the three experimental groups and the MannWhitney $U$ test was used when the EXP and EXA groups were compared with the CTL group. P-values of less than 0.05 were considered to be statistically significant.

\section{RESULTS}

8-OHdG levels in the EXP saliva were significantly higher $(16.33 \pm 4.33 \mathrm{ng} / \mathrm{ml})$ than in the CTL group $(8.92 \pm$ $0.77 \mathrm{ng} / \mathrm{ml})$ and the EXA group $(9.56 \pm 1.82 \mathrm{ng} / \mathrm{ml})(\mathrm{p}<0.01)$ (Fig. 1). On the other hand, $8-\mathrm{OHdG}$ levels in the sera of the EXP mice $(6.59 \pm 4.33 \mathrm{ng} / \mathrm{ml})$ were not significantly different compared with the CTL $(6.99 \pm 0.46 \mathrm{ng} / \mathrm{ml})$ and EXA groups $(6.83 \pm 0.78 \mathrm{ng} / \mathrm{ml})$, thus suggesting that $8-\mathrm{OHdG}$ was secreted from the salivary gland, but was not present in serum.

\section{DISCUSSION}

The present study demonstrated a significant increase of the oxidative stress marker $8-\mathrm{OHdG}$ in saliva in mice undergoing long-term exercise training under diet restrictions. Because there were no increases in HEL or m-GOT levels (date not shown), the guanine in DNA underwent oxidative damage by ROS without apparent occurring lipid peroxidation or cell damage. In the group of mice with long-term exercise and without food restrictions, changes in the saliva secretion and salivary protein contents were not recognized, and the level of salivary $8-\mathrm{OHdG}$ was not altered. Therefore, these results suggest that an increase in oxidative stress markers in saliva is related to the alteration of salivary secretion and qualitative changes in salivary proteins.

The oxidative stress is related to various mechanisms such as apoptosis, cancer progression, inflammation and aging. There are many putative roles for nitric oxide (NO) in the salivary glands, and include ensuring an adequate blood supply during long-term salivary secretion, serving as a feedback mechanism to the periacinar neurones, regulating cell growth and differentiation in the surrounding tissue, and participating in the host defense barrier [15]. Regarding the role of NO signaling in salivary secretion, $\beta$-adrenergic receptor stimulation activates NO production via NO synthase (NOS). Both endogeneous and exogeneous NO activate cGMP synthesis and $\mathrm{G}$ kinase. Following activation of the $\mathrm{NO} / \mathrm{cGMP} / \mathrm{G}$ kinase pathway, the $\mathrm{Ca}^{2+}$ signal induced by stimulation of the PLC-coupled receptor, muscarinic and alpha-adrenergic receptors, is amplified, forming the basis for propagated secretion (15). On the other hand, NO has been shown to play a role in the pathogenesis of a number of oral diseases. Aberrant NO production in the acinar cells may contribute to the disease progression in Sjögren's syndrome $[15,16]$. The levels of $8-\mathrm{OHdG}$ have been shown to 
(A)

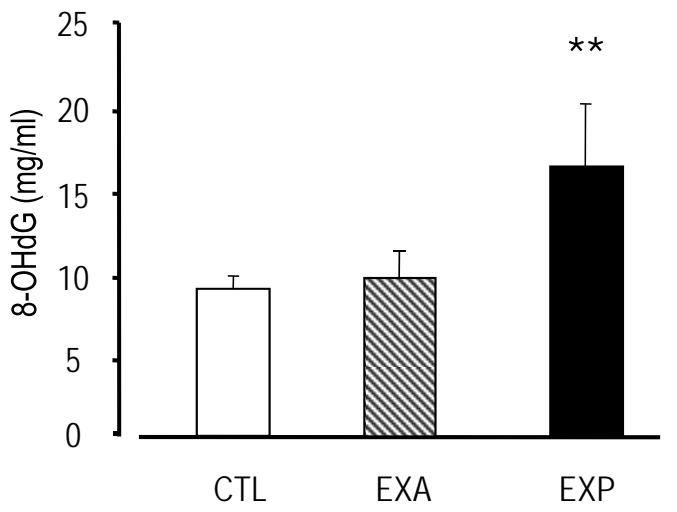

(B)

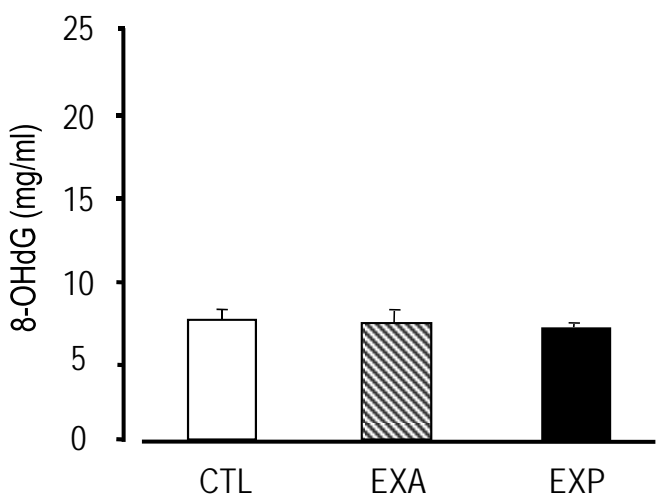

Fig. (1). Changes of saliva and serum $8-\mathrm{OHdG}$.

Saliva is collected from the oral cavity for $15 \mathrm{~min}$ after the injection of pilocarpine. The 8-OHdG levels were assessed by competitive enzyme-linked immunosorbent assay (ELISA) using an $8-\mathrm{OHdG}$ monoclonal antibody. The $8-\mathrm{OHdG}$ levels are indicated in saliva (A) and serum (B). Values of saliva are the means \pm SD of nine mice in the CTL, six mice in the EXA, five mice in the EXP. Values of serum are the means \pm SD of six mice in the CTL, five mice in the EXA, five mice in the EXP. ${ }^{*} p<0.01$, Mann-Whitney's $U$ test.

increase in the saliva of patients with Sjögren's syndrome [7].

Increase of salivary $8-\mathrm{OHdG}$ is thought to be due oxidative damage of the salivary glands. One of the possible reasons in the increase of oxidative stress is speculated to be chronic stimulation of adrenergic receptor. Isoproterenol induces cAMP via $\beta$-adrenergic receptor stimulation, and cAMP-dependent protein kinase A (PKA), which is activated by cAMP, stimulates the secretion of salivary proteins. Isoproterenol-stimulated secretion is associated with increased oxygen and glucose consumption [17]. Lipid peroxidation in the submandibular gland is increased following a single injection of isoproterenol, and accordingly the activity of the antioxidative enzyme superoxide dismutase (SOD) is increased [18]. Reactive oxygen species (ROS) such as superoxide anion, hydroxyl radicals, and hydrogen peroxide are constantly produced in aerobic organisms. The superoxide dismutases (SOD) are antioxidative enzymes that act as a first defense against oxidative stress [18]. Long-term physical exercise under dietary control is speculated to induce physical and/or mental stress, and therefore causes chronic stimulation of the sympathetic receptors [4]. Salivary oxidants might be increased by chronic and excessive $\beta$ adrenoceptor stimulation as a result of the imbalance of oxidants and antioxidants, namely the accumulation of ROS and the anti-ROS SOD activity.

In isolated rat mesenteric arteries, selective stimulation of alpha $a_{1}$-adrenoceptors with phenylephrine induced matrix metalloproteinase (MMP) transactivation of the epidermal growth factor receptor (EGFR), mitochondrial ROS production and vasoconstriction [19]. The study suggests that vascular disease is established by adrenoceptor stimulation, and oxidative stress contributes to this process. The mechanism is an attractive one to explain the results of the present study. The decrease of salivary kallikrein activity in mice undergoing chronic exercise training under dietary restriction might occur as a result of ROS production.

Chronic stress is known to affect salivary gland function. Chronic exposure of rats to light promotes the degradation of parotid acini and the desensitization of submandibular gland $\beta$-adrenergic receptors [20], and alpha ${ }_{2}$-adrenergic desensitization was observed in these constant light-exposed rats as well as restraint-stress rats, in which $2 \mathrm{~h}$ daily immobilization was induced for 14 days [21]. Because the localization changes of these receptors following agonist stimulation are well-known phenomena, there is a possibility that desensitization occurs under stress conditions such as physical exercise training under dietary-restricted conditions. Since kallikrein is secreted in response to alpha $a_{1}$-adrenergic receptor stimulation [5], down regulation might be involved in the alpha $_{1}$-adrenergic receptor stimulation.

The present study suggests the involvement of oxidative stress in salivary changes due to chronic stress. Therefore, further investigations into the participation of NO and ROS and their role in the intracellular signal transduction are required.

\section{ACKNOWLEDGEMENT}

Funding: This study was supported in part by a Grant-inAid for Scientific Research from Ministry of Education, Culture, Sports, Science and Technology of Japan.

Ethical approval: All experimental procedures were carried out in accordance with the European Convention for the Protection of Vertebrate Animals used for Experimental and Other Scientific Purposes and were approved by the Committee on Animal Care of Tsurumi University School of Dental Medicine.

\section{REFERENCES}

[1] Bauman AE. Updating the evidence that physical activity is good for health: an epidemiological review 2000-2003. J Sci Med Sport 2004; 7(1 Suppl): 6-19.

[2] Ogonovszky H, Sasvari M, Dosek A, et al. The effects of moderate, strenuous, and overtraining on oxidative stress markers and DNA repair in rat liver. Can J Appl Physiol 2005; 30(2): 186-95.

[3] Kimura F, Aizawa K, Tanabe K, et al. A rat model of saliva secretory immunoglobulin: a suppression caused by intense exercise. Scand J Med Sci Sports 2008; 18(3): 367-72.

[4] Yoshino Y, Yamane A, Suzuki M, Nakagawa Y. Availability of saliva for the assessment of alterations in the autonomic nervous system caused by physical exercise training. Arch Oral Biol 2009; 54(11): 977-85. 
[5] Rabito SF, Ørstavik TB, Scicli AG, Schork A, Carretero OA. Role of the autonomic nervous system in the release of rat submandibular gland kallikrein into the circulation. Circ Res 1983; 52: 635-41.

[6] Nagler RM, Salameh F, Reznick AZ, Livshits V, Nahir AM. Salivary gland involvement in rheumatoid arthritis and its relationship to induced oxidative stress. Rheumatology (Oxford) 2003; 42(10): 1234-41.

[7] Ryo K, Yamada H, Nakagawa Y, et al. Possible involvement of oxidative stress in salivary gland of patients with Sjogren's syndrome. Pathobiology 2006; 73(5): 252-60.

[8] Kasai H, Crain PF, Kuchino Y, Nishimura S, Ootsuyama A, Tanooka H. Formation of 8-hydroxyguanine moiety in cellular DNA by agents producing oxygen radicals and evidence for its repair. Carcinogenesis 1986; 7(11): 1849-51.

[9] Halliwell B, Aruoma OI. DNA damage by oxygen-derived species. Its mechanism and measurement in mammalian systems. FEBS Lett 1991; 281(1-2): 9-19.

[10] Shigenaga MK, Gimeno CJ, Ames BN. Urinary 8-hydroxy-2'deoxyguanosine as a biological marker of in vivo oxidative DNA damage. Proc Natl Acad Sci USA 1989; 86(24): 9697-701.

[11] Suzuki M, Satoh Y, Hashiba N. Effect of voluntary running exercise on hypertriacylglycerolemic effect of sucrose in relation to its feeding timing in rats. J Nutr Sci Vitaminol (Tokyo) 1983; 29(6): 663-70.

[12] Kamei Y, Miura S, Suzuki M, et al. Skeletal muscle FOXO1 (FKHR) transgenic mice have less skeletal muscle mass, downregulated Type I (slow twitch/red muscle) fiber genes, and impaired glycemic control. J Biol Chem 2004; 279(39): 41114-23.
[13] Sreebny LM, Johnson DA. Effect of food consistency and decreased food intake on rat parotid and pancreas. Am J Physiol 1968; 215(2): 455-60.

[14] Hall HD, Schneyer CA. Salivary gland atrophy in rat induced by liquid diet. Proc Soc Exp Biol Med 1964; 117: 789-93.

[15] Looms D, Tritsaris K, Pedersen AM, Nauntofte B, Dissing S. Nitric oxide signalling in salivary glands. J Oral Pathol Med 2002; 31(10): 569-84.

[16] Konttinen YT, Platts LA, Tuominen S, et al. Role of nitric oxide in Sjogren's syndrome. Arthritis Rheum 1997; 40(5): 875-83.

[17] Nicolau J, Sassaki KT. Metabolism of carbohydrate in vitro of the submandibular salivary glands (SMG) from mice injected with isoproterenol. Gen Pharmacol 1983; 14(6): 705-8.

[18] Barroso AS, Quissell DO, Colepicolo P. Modulation of SOD activity in rat submandibular glands. Arch Oral Biol 2003; 48(2): 133-9.

[19] Hao L, Nishimura T, Wo H, Fernandez-Patron C. Vascular responses to alpha ${ }_{1}$-adrenergic receptors in small rat mesenteric arteries depend on mitochondrial reactive oxygen species. Arterioscler Thromb Vasc Biol 2006; 26(4): 819-25.

[20] Gallara RV, Bellavia SL. Modification of the beta-adrenergic sensitivity of rat submandibular gland by constant light. Arch Oral Biol 1995; 40(1): 73-7.

[21] Bellavia SL, Gallara RV. Modification of the beta- and alpha $2^{-}$ adrenergic sensitivity of rat submandibular glands by environmental stimuli and stress. Arch Oral Biol 1998; 43(12): 933-9.

(C) Yoshino and Nakagawa; Licensee Bentham Open.

This is an open access article licensed under the terms of the Creative Commons Attribution Non-Commercial License (http://creativecommons.org/licenses/by-nc/3.0/) which permits unrestricted, non-commercial use, distribution and reproduction in any medium, provided the work is properly cited. 